\title{
Reconstrucción periodística de nuevas formas de vida democrática (la "Marcha del Silencio", abril de 2005)
}

\author{
Eva Salgado Andrade \\ y Frida Villavicencio Zarza
}

Se analizan los titulares y subtitulares de la primera plana de 15 periódicos mexicanos publicados el 25 de abril de 2005, el día siguiente de la "Marcha del Silencio" en la ciudad de México, en la que casi I 200000 manifestantes protestaron contra el desafuero del jefe de gobierno capitalino Andrés Manuel López Obrador. El análisis del material lingüístico de los titulares permitió advertir si la prensa consideró más relevante la celebración de la marcha o si destacó a un protagonista individual. Los resultados muestran que la mayoría de la prensa no estaba preparada para dar relevancia al sentido democrático de la marcha y optó por resaltar el sentido electoral del episodio, que a la postre se convertiría en uno de los primeros capítulos de la polémica contienda por la presidencia en 2006.

PALABRAS CLAVE: discurso, prensa, titulares, Marcha del Silencio, Andrés Manuel López Obrador, movilización política

\section{Journalistic Reconstruction of New Ways of Democratic Life (the "March of Silence", April 2005)}

We analyze the main headlines and subheads on the front page of 15 Mexican newspapers published on $25^{\text {th }}$ April of 2005, next day of the March of Silence, when nearly I 200000 demonstrators protested against the Mexico City local governor's Andrés Manuel López Obrador suppression of legal immunity. The analysis of the linguistic material of the headlines reveal if the press considered the march as the most relevant topic or if focused on a single protagonist. The results show that most of the press was not ready to give prominence to the democratic spirit of the march and chose instead to emphasize the electoral sense in this episode, which eventually became one of the first chapters of the controversial 2006 presidential elections.

KEYWORDS: discourse, press, headlines, March of Silence,Andrés Manuel López Obrador, political mobilization

\footnotetext{
Eva SALgado ANDrade: Centro de Investigaciones y Estudios Superiores en Antropología Social-Distrito Federal, México esalgado@ciesas.edu.mx
}

Frida Villavicencio Zarza: Centro de Investigaciones y Estudios Superiores en Antropología Social-Distrito Federal, México frida@ciesas.edu.mx 
... a los movimientos populares se les ha presentado como producidos por el hambre, los impuestos, el paro: nunca como una lucha por el poder, como si las masas pudiesen soñar con comer bien pero no con ejercer el poder. La historia de las luchas por el poder, y en consecuencia las condiciones reales de su ejercicio y de su sostenimiento, sigue estando casi totalmente oculta.

Michel Foucault (1979: 32).

\section{INTRODUCCIÓN. EL SILENCIO EN MARCHA}

$\mathrm{E}$ 124 de abril de 2005 tuvo lugar la "Marcha del Silencio", protagonizada por cientos de miles de ciudadanos que recorrieron el largo trayecto del Museo de Antropología hasta el Zócalo capitalino, corazón político de la República Mexicana. Sus principales consignas eran la defensa del sufragio efectivo, la legalidad y la institucionalidad, y el repudio al desafuero del que había sido objeto el entonces jefe de Gobierno del Distrito Federal de maniobras políticas orquestadas por el gobierno federal, la Procuraduría General de la República (PGR) y las fracciones de los partidos Acción Nacional (PAN) y Revolucionario Institucional (PRI) de la Cámara de Diputados, con el aparente fin de inhabilitar al funcionario en la eventual contienda por la sucesión presidencial de 2006.

Los principales antecedentes políticos de este acontecimiento, profusamente difundidos por los medios de comunicación, se remontan a 2004, cuando se responsabilizó a López Obrador de haber violado una orden judicial que exigía suspender la construcción de una calle en un terreno expropiado años atrás. $\mathrm{Si}$ bien los trabajos fueron suspendidos, se alegó dilación en el cumplimiento de la orden. El gobierno de Vicente Fox, por medio de la PGR, solicitó al Congreso despojar al gobernante local del cargo para que enfrentara el proceso judicial. En sesión celebrada el 7 de abril de 2005 en la Cámara de Diputados, con 360 votos a favor, 127 en contra y dos abstenciones, los legisladores aprobaron el desafuero.

Buena parte de la opinión pública criticó la decisión con el argumento de que se había tratado de una maniobra que, más allá de velar por el cumplimiento de la ley, trataba de impedir que López Obrador pudiese contender en las elecciones del año siguiente, más aun cuando algunas encuestas lo ubicaban con varios puntos de ventaja sobre otros posibles candidatos. El malestar colectivo crecía al considerar que esta afrenta a la democracia surgía precisamente del gobierno electo en el proceso ejemplar de 2000, que había dado fin al gobierno hegemónico priista para colocar por vez primera a un panista en la presidencia. Resultaba irónico que precisamente un gobierno que no dejaba de reconocer su deuda con la democracia atentara contra ella de manera tan flagrante. ${ }^{1}$

La indignación pública frente a esta estrategia fue contundente en la marcha del 24 de abril de 2005, una de las movilizaciones pacíficas más importantes en la historia reciente del país. Resalta, en primer término, la capacidad de respuesta de los convocantes. Es imposible determinar con certeza el número de personas que concurrieron, aunque varios medios coincidieron en que fueron más de 1200000 . Respecto de este tema, es interesante referir la disparidad en las cifras oficiales que ofrecieron las policías capitalina y federal. En el primer caso, la Secretaría de Seguridad Pública (ssp) del Distrito Federal confirmó la cantidad mencionada, corroborada por la mayoría de reporteros y articulistas al día siguiente. Cifras oficiales de la Policía Federal Preventiva (PFP) reportaron la asistencia de "sólo 120000 personas".

\footnotetext{
${ }^{1} \mathrm{Al}$ paso del tiempo estas sospechas quedaron plenamente confirmadas. Aziz (2007: 13) registró las palabras de Vicente Fox durante una conferencia en Washington, reproducidas en $E l$ Universal, el 13 de febrero de 2007: "[con el desafuero de López Obrador] tuve que retirarme y perdí. Pero 18 meses después me desquité cuando ganó mi candidato".

${ }^{2}$ Este intento por tratar de minimizar el hecho fue ampliamente criticado. Por ejemplo, en su sección "Rayuela" del día siguiente, el diario La Jornada publicaba este irónico comentario: "El ingenio popular desplegado ayer en la ciudad sólo fue superado por el genio contable de Martín Huerta [a la sazón, secretario de la PFP] con sus ' 120000 manifestantes".
} 
Otro elemento relevante fue el silencio como expresión de indignación generalizada. Durante el recorrido era impactante la ausencia total de gritos de consigna. Para reforzar el pacto de silencio muchos de los manifestantes portaban pañuelos, paliacates o tapabocas de color blanco o azul, con un moño tricolor estampado. Destacaba también la heterogénea composición de la manifestación, de todos los rangos de edades y de muy diversos estratos socioeconómicos. Si bien se observó la presencia de contingentes - partidistas, sindicales, vecinales o estudiantiles, entre otros-, buena parte de quienes recorrieron los poco más de seis kilómetros iban en pequeños grupos de amigos, en pareja, solitarios o incluso con toda la familia.

El silencio de los manifestantes se completó con una nutrida gama de objetos y elementos gráficos. Mantas, pancartas, cartulinas, globos, camisetas estampadas y disfraces constituyeron, en su conjunto, un gran complejo semiótico con el cual miles de ciudadanos expresaban su indignación ante un hecho que, más allá de agraviar a un personaje político, representaba una afrenta hacia la democracia. "No al desafuero", "No estás solo", "Ni tú ni yo tenemos fuero, pero Fox y Creel ¡NO TIENEN MADRE!", “Nosotros los López, ustedes los ricos", "Peje el Toro es inocente", eran algunas de las consignas más leídas. En un complejo ejercicio de intertextualidad, los marchistas se hicieron acompañar de toda suerte de personajes, reales o ficticios: Don Quijote de la Mancha blandía una enorme lanza al lado de un Rocinante hecho de huacales de madera, numerosos ataúdes con el "cadáver" de la democracia, el Caballo de Troya, Benito Juárez o la mismísima Virgen de Guadalupe, entre muchos otros.

Por último, esta movilización es memorable porque contribuyó a cumplir su objetivo principal: revertir el proceso de desafuero. En efecto, cinco días después de la marcha y de su contundente mensaje, Vicente Fox se vio obligado a buscar una salida política para el caso, cuando dio a conocer en un mensaje a la nación la renuncia de Rafael Macedo de la Concha, titular de la PGR, luego de anunciar que se había revisado el expediente de consignación de López Obrador. Se comprometió públicamente a comportarse como presidente de un auténtico país democrático ${ }^{3}$ y a no impedir a nadie participar en la contienda electoral. Por todo lo anterior, la "Marcha del Silencio" continúa vigente en la memoria colectiva y es de interés para ser examinada desde diversos aspectos, al ser emblemática para la comprensión de nuevas formas de acción democrática en nuestro país. Elsa Rodríguez Saldaña propone una definición genérica para este tipo de expresiones de movilización social:

La marcha es una invitación a agregarse, una masa abierta insaciable y de efímera existencia, que celebra el hecho de reunir provisionalmente aquello que la cotidianeidad separa: un conjunto de subjetividades que claman por justicia, por una ciudadanía no sólo de nombre (Rodríguez, 2008: 109).

La "Marcha del Silencio" era, sin lugar a dudas, un vehemente llamado a la justicia. Cabría pensar, en consecuencia, que este llamado a respetar la democracia podría ser el tema principal de la prensa el día siguiente. A fin de cuentas, los medios de comunicación han tenido un incuestionable papel histórico en el surgimiento de instituciones democráticas (Chilton y Schäffner, 2002: 8). En efecto, el lunes 25 de abril el evento fue tema de las primeras planas, con excepción de La Prensa, que cedió el lugar principal al recién ungido Papa Benedicto XVI, y envió la nota de la marcha a la contraportada. Hay que tener presente la complejidad informativa de un hecho como el que se reseñaba, de indudable interés para un amplio público, pero sobre el cual era previsible que operasen algunas selecciones para destacar unos temas sobre otros. Basta ver, a manera de ejemplo, algunas de las formas en que la prensa aludió a la movilización:

\footnotetext{
${ }^{3}$ Aunque distó de cumplir con este ofrecimiento, como pudo comprobarse una y otra vez durante 2006.
} 
El acarreo de López./ El Mega acarreo./ Impresionante multitud./ La más grande concentración humana en la República Mexicana./ La "marcha silenciosa" protagonizada ayer por militantes del Partido de la Revolución Democrática (PRD) y simpatizantes del desaforado jefe de Gobierno del Distrito Federal, Andrés Manuel López Obrador./ La entronización del candidato que, como dice la canción, "como un pez se le escurrió" a la PGR./ La estela de nueve kilómetros presuntamente silenciosa, gritona más de las veces, desordenada./ La llamada "marcha del silencio”./ La manifestación pro López./ La marcha de la victoria./ La marcha política más numerosa de la historia en el país./ Marcha ruidosa./ Mitin en contra del desafuero de Andrés Manuel López Obrador./ Multitud de 7 mil metros que no pudo enmudecer. / Parte de las acciones de resistencia civil contra el desafuero del jefe de Gobierno del Distrito Federal, Andrés Manuel López Obrador./ Plebiscito en contra de Vicente Fox./ Un frenón al golpe democrático de Fox y compañía./ Una de las más grandes concentraciones habidas en el Zócalo de la ciudad de México./ Una manifestación contundente que muestra a un Andrés Manuel López Obrador al que su estrategia de mártir y los burdos y torpes ataques de sus enemigos, han fortalecido./ Una muchedumbre reunida en la Plaza de la Constitución (Salgado, 2009: 180-181).

En la cobertura periodística del 25 de abril, la movilización competiría con otro tema de marcado interés mediático durante varias décadas en México: el "destape" de un candidato presidencial. La transformación de un sistema político unipartidista, iniciada en el año 2000, no implicaba necesariamente la ruptura con viejas prácticas políticas que han caracterizado al país durante décadas, en las que "una vez que se daba a conocer al candidato - conocido entre la jerga popular como el "tapado" - se le rendían honores pues tácitamente su reinado había comenzado" (Salgado, 2003: 107).

Con base en las evidencias discursivas, el mensaje silencioso transmitido por los ciudadanos fue objeto de una reconversión al llegar al día siguiente a la primera plana de los diarios. Kurzon (1998: 5) argumenta que, si bien el silencio es altamente significante, el problema central para el discurso es descubrir su sentido. Saville-Troike (1985: 11) también ha realizado estudios en torno a la capacidad expresiva del silencio. En su "Introducción" para Perspectives on Silence, arguye que el silencio tiene una gran fuerza ilocucionaria, en tanto puede ser utilizado para cuestionar, prometer, negar, amenazar, insultar, pedir $\mathrm{u}$ ordenar. Al confrontar la manera en que, al día siguiente, la prensa dio testimonio de este episodio en sus primeras planas, el sentido del silencio de los manifestantes pareció haber sido silenciado. Fairclough y Wodak (2000: 367) sostienen que el discurso, en tanto práctica social, mantiene una relación dialéctica con las situaciones, instituciones y estructuras sociales, es decir, está moldeado por ellas pero también contribuye a darles forma. En función de esta relación dialéctica, van Leeuwen (1993: 193) propone que el discurso se orienta fundamentalmente hacia dos vertientes: como instrumento del poder y como instrumento de construcción social de la realidad.

\section{TITULARES DE LA PRENSA. PRAGMÁTICA EN ACCIÓN}

Para la construcción del corpus disponíamos de un amplio acervo periodístico, ${ }^{4}$ del que consideramos relevante lo publicado en el encabezado principal. Respecto de las "rutas de lectura" y el supuesto orden en que el lector atiende a la información en prensa, Kress y van Leeuwen (1998: 206) afirman que éste inicia con la lectura de la primera plana. Los titulares representan una selección y una jerarquización que pone de manifiesto el punto de vista de quien los produce; la selección del tema, la redacción y la presentación gráfica del titular que ocupa la nota de primera plana son indicadores relevantes

\footnotetext{
${ }^{4} \mathrm{Al}$ recopilar el acervo íntegro de notas publicadas en los 15 diarios se registró un total de 194 notas, crónicas, entrevistas, editoriales, caricaturas políticas, fotografías y reportajes que se ocupan de "lo ocurrido" durante la jornada. Su análisis sería una tarea interesante, pero por ahora, por razones de tiempo y espacio, debemos dejarlo de lado.
} 
para entender la posición - política, económica y social- desde la cual un periódico relata un hecho noticioso.

De esta manera, el corpus se integró por 15 titulares y sus correspondientes subtitulares publicados en la primera plana o en la contraportada - para el caso de La Prensa - de 15 periódicos puestos en circulación para venta o distribución gratuita el 25 de abril de 2005 en la ciudad de México (véase tabla 1): Diario de México, El Financiero, El Gráfico, El M, El Sol de México, El Universal, Excélsior, Impacto El Diario, La Crisis, La Crónica de Hoy, La Jornada, La Prensa, Metro, Milenio Diario y Reforma, que en conjunto ofrecían un registro amplio y representativo de la prensa impresa y distribuida en el Distrito Federal, independientemente de su mayor o menor relevancia política, mediática o incluso mercantil. Ofrecemos ahora algunos datos mínimos en relación con el conjunto de diarios seleccionados y los criterios para su selección, con el fin de contribuir a una mejor contextualización de los materiales que presentaron y del análisis realizado sobre los mismos.

Era incuestionable la inclusión de un diario como La Jornada, cuya aparición se remonta a 1984. Este diario había mantenido una posición crítica hacia el gobierno federal, tanto en los regímenes priistas como durante la gestión de Vicente Fox, al tiempo que mostraba simpatía hacia el gobierno local capitalino en sus diversas administraciones. La de López Obrador no era la excepción. De hecho, la cobertura periodística privilegiada de la marcha quedaba de manifiesto con la innovación en el diseño gráfico del lunes 25 de abril de 2005: una portada exterior a doble página en concordancia con las dimensiones del acontecimiento mostraba el impresionante mar de personas que se habían dado cita en el Paseo de la Reforma.

El Reforma, publicado a partir de 1993, era reconocido como un periódico con gran potencial no sólo político sino económico, ligado con poderosos grupos empresariales del norte del país. Conviene recordar que a fines de 1994, apenas un año después de que comenzara a ser publicado, tuvo un conflicto con la Unión de Voceadores y Expendedores de
Periódicos de México, que se negó a distribuir ejemplares en los quioscos y otros puntos de venta, situación que parecía amenazar su subsistencia. Sus editores, con el apoyo de reporteros, colaboradores, algunos diputados federales, artistas e intelectuales, decidieron crear su propio mecanismo de venta directa al público. De este modo, no sólo pudieron remontar la situación adversa, sino que aumentaron considerablemente su fuerza de ventas. La misma empresa que edita Reforma publica Metro, un tabloide sensacionalista de menor precio, concebido para un universo de lectores de estratos socioeconómicos más bajos, el cual igual quedó agregado en la muestra.

Incorporamos asimismo al decano de los medios impresos en México, El Universal, que se publica de manera ininterrumpida desde 1916. En su larga

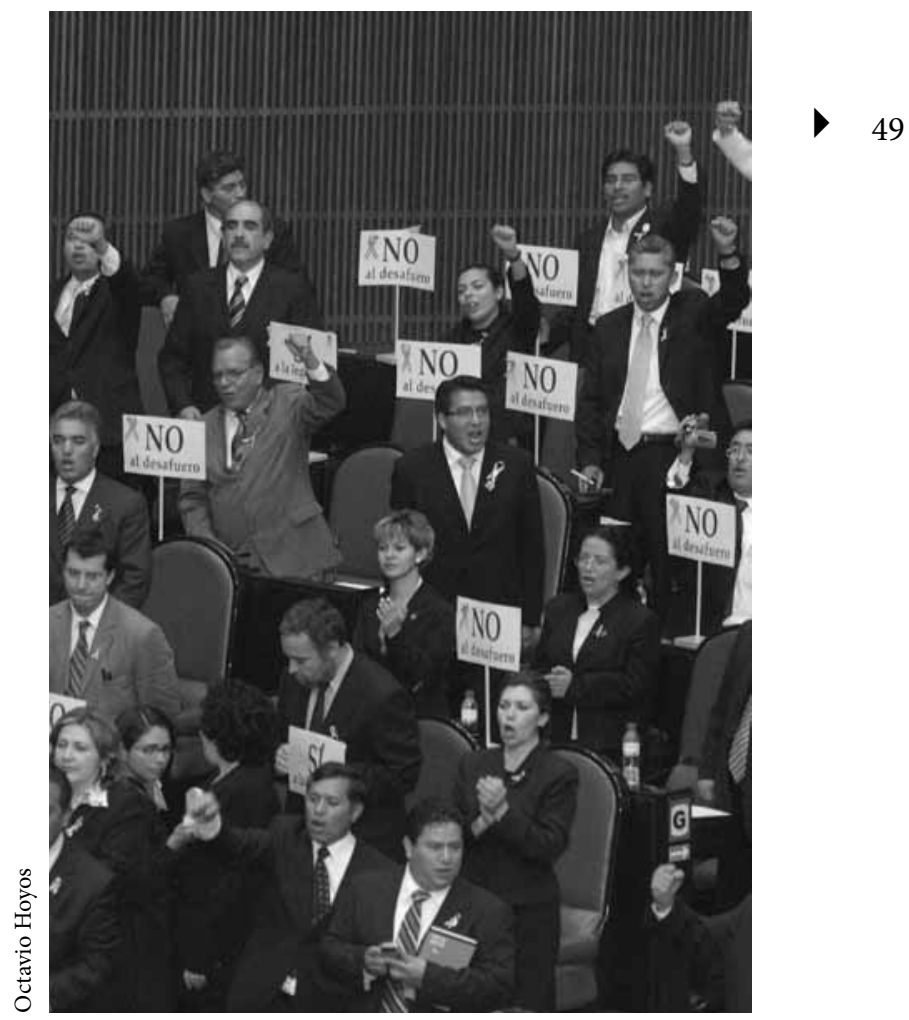

Sesión de la Cámara de Diputados en la que se decidió el desafuero de Andrés Manuel López Obrador, 2005. 
trayectoria se le ha calificado como un diario conservador, si bien sus columnas de opinión suelen ser reconocidas como plurales. También edita El Gráfico, tabloide sensacionalista dirigido a un sector socioeconómico de menores recursos, y $E l M$, periódico gratuito cuyo objetivo era la venta de espacios publicitarios y que se distribuía entre usuarios del Sistema de Transporte Colectivo Metro. Con el afán de cubrir un universo lo más amplio posible en cuanto a tendencias políticas y espectro potencial de lectores incorporamos La Prensa, que data de 1928 y es uno de los diarios sensacionalistas de mayor arraigo y de los más leídos en la ciudad de México. En el año de este estudio ya formaba parte de la empresa Organización Editorial Mexicana (oEM), cuya peculiaridad es dirigirse de manera focalizada a mercados locales en diversas entidades del país, para lo que se vale de un universo de 70 diarios, entre los que se encuentra $\mathrm{El} \mathrm{Sol} \mathrm{de} \mathrm{México,} \mathrm{que} \mathrm{también} \mathrm{está} \mathrm{en} \mathrm{la}$ muestra.

Se seleccionaron otros dos diarios de información Excélsior y Diario de México. El primero de ellos ha protagonizado una historia importante en el periodismo nacional. Uno de sus episodios paradigmáticos fue la salida de Julio Scherer y un numeroso grupo de reporteros en 1976, que daría lugar a la creación de Proceso y unomásuno. Sin embargo, en el año del estudio su destino parecía agonizante y sus fuerzas políticas y de ventas estaban considerablemente mermadas. Esta circunstancia cambió al ser adquirido por Olegario Vázquez Raña, del Grupo Imagen, en 2006, en el marco de las elecciones, cuando se renovó su diseño y se sumaron a sus planas destacados analistas políticos. Diario de México es una publicación que ha mantenido una presencia modesta, pero ininterrumpida, durante muchos años, sobre todo en la ciudad de México, en particular por la venta de espacios publicitarios. Por ejemplo, en él se publica buena parte de los edictos judiciales.

Incluimos un diario relativamente joven en el ambiente político, Milenio Diario, que comenzó a publicarse en el año 2000 de manera coyuntural con la intensa campaña electoral. En el año de este estudio parecía gozar de cierto reconocimiento como una opción informativa, si no crítica, por lo menos plural en la escena política. Dado el personaje involucrado en este episodio, no podía faltar La Crónica de Hoy, fundado en 1996, que invariablemente había mantenido una postura crítica hacia el jefe del GDF -en este diario fue recurrente hacer referencia a AMLO como "López" a secas, hasta que adquirió una connotación despectiva-. Los tiempos políticos recientes han dado lugar, entre otros fenómenos, a la aparición de diarios de existencia fugaz, generalmente ligados con otros proyectos editoriales o de comunicación. En abril de 2005 detectamos dos: $\mathrm{La}$ Crisis - que en 2005 alcanzaba su tercer año de vida, publicado por la misma empresa que editaba la revista del mismo nombre- e Impacto El Diario -medio aún más joven, con apenas 105 números y que en esos días intentaba sin mucho éxito mantener a flote la presencia que durante años había ostentado la desaparecida revista política Impacto- - Por último, añadimos un periódico especializado en economía, El Financiero, para observar cómo un hecho coyuntural puede provocar cambios en los formatos habituales de los periódicos.

Como señalábamos en la introducción, la brevedad de los titulares principales da pie a interesantes reflexiones sobre la lengua y sus usos, es decir, sobre los mecanismos lingüísticos y pragmáticos de los que dispone el hablante para satisfacer sus necesidades comunicativas. Los titulares de prensa desempeñan un papel central en el discurso periodístico, "abren" el discurso y establecen los temas que el periódico reconoce como de máxima importancia. En cierto sentido, los titulares de prensa, por su contenido y por su forma, constituyen un subtipo de texto, que se distingue por ser doblemente marcado. ${ }^{5} \mathrm{La}$

\footnotetext{
${ }^{5}$ En la lingüística contemporánea la noción de marcación, desarrollada originalmente por los lingüistas de Praga, se usa ahí donde un rasgo particular tiene, en un sentido amplio, dos o más valores, uno como el más acostumbrado, el más esperado, el más natural que los otros. Este valor más usual se denomina "no marcado", el otro valor o valores son llamados "marcados" (Comrie, 1996).
} 
Tabla 1. Principales titulares y subtitulares en relación con la "Marcha del Silencio", 25 de abril de 2005

a) ¡VUELVE!

Desde esta madrugada López Obrador regresó a trabajar en su oficina; logra reunir a miles en Marcha del Silencio / Propone un pacto sin revanchismos / Cuauhtémoc sí participó / Todos lo quieren desaforadamente / Saldo blanco en la concentración / No odiamos ni buscamos venganzas (La Prensa).

b) López Retador: Reasumirá hoy Llama a Deponer el Encono / Cientos de Miles vs. Desafuero / Se integró hasta El Ángel. “¡Ay, Andrés! Ni aquí cumples..." y tiró la flor al suelo (Excélsior).

c) Pide López Obrador detener encono

1 millón 200 mil, según ssp capitalina. 120 mil participantes, reportó la ssp federal. Mil 699 elementos vigilaron el trayecto / Vuelve hoy a la Jefatura de Gobierno del DF, confirma / Incurrirá en delito: PGR / Marcha que se resistió al silencio (El Universal).

d) Plantea AmLo pacto de unidad

Llama a unificar el país "de manera menos conflictiva”; el apoyo popular no basta, reconoce / Pide no temer a su proyecto de izquierda; "no odiamos ni buscamos venganza" / Exhorta a sus adversarios a deponer el encono y anuncia plan de Gobierno ante miles de marchistas (El Sol de México).

e) Llama AMLO a poner fin al encono

Marcharon al zócalo cientos de miles / "Sufragio efectivo, no descalificación" / Movilizaciones en París, Barcelona, Madrid, Nueva York, Washington, Sydney, Quebec y Copacabana (Milenio Diario).

\section{f) Discurso conciliador de AMLO; ofrece no volver al estatismo (El Financiero).}

g) Conciliador, pide pacto

López Obrador en marcha multitudinaria / Reúne a cientos de miles de personas y propone tregua para emprender los cambios que requiere el país / Muñoz Ledo afirmó que la democracia está en peligro. Fue abucheado / sSPT 120 mil. sspDF millón 200 mil. Organizadores millón 300 mil / "Sigo siendo Jefe de Gobierno" / "Pensamos distinto, pero no hay motivo para que nadie se alarme; no hay que imaginar cosas que no van a suceder" / "No seremos nosotros los que dañemos a México" (Impacto El Diario).

h) Sin cargos, con recursos públicos, AMLO arranca

López regresa hoy a su oficina: "sigo siendo el jefe de GDF" / Empleados de Atención Ciudadana del gobierno capitalino hicieron vallas / Policías efectuaron tareas de franeleros / Trasladaron autobuses públicos a viejitos / Usaron helicóptero de ssP con fines propagandísticos (La Crónica de Hoy).

i) ¡Arranca!

López Obrador olvida desafuero; delinea su proyecto basado en combate a la pobreza / Hoy regresa al GDF; será un delito: PGR (El Gráfico).

j) Autodestape (La Crisis).

k) AMLo informó de su proyecto de gobierno

Propone un pacto con sectores / Cientos de miles en la marcha / Vuelve hoy a la Jefatura del DF (Diario de México).

l) MUEVE TROPAS

Marchan miles con AMLo / Reporta el GDF 1 millón de personas: son 120 mil, dice el Gobierno Federal / López Obrador marchó al Zócalo acompañado de Yeidckol Polevnsky y sus hijos (Metro).

m) Moviliza 'tropas' y regresa al GDF

Marchan cientos de miles por AMLO; modera su discurso y anuncia que hoy supervisará obras (Reforma).

n) Rompen el silencio

La marcha convocada por AMLO para protestar por el desafuero se convirtió en un mitin de apoyo políticoelectoral / Con miras al 2006 detalla López Obrador su proyecto alternativo de nación y llama a crear un pacto social para realizar cambios en el país $(E l M)$.

o) Más de un millón repudiaron el abuso del poder

AMLO: miedo irracional al proyecto alternativo de país / El gobernante regresa hoy al GDF a "supervisar obras y programas" (La Jornada). 
noción de marcación puede ser aplicada a la parte gráfica de la comunicación escrita. En el caso de los titulares, la tipografía especial mediante la cual se los codifica - que se distingue por tamaño, grosor, tipo e incluso color- reafirma al lector el lugar privilegiado que se les confiere dentro del discurso periodístico. Una letra que se distingue de alguna manera de la utilizada en el cuerpo del texto constituye un recurso iconográfico convencional para destacar partes de un texto, es un indicador abierto de la importancia que la fuente redactora confiere a ese contenido. La posición inicial absoluta que los titulares de prensa ocupan dentro del cuerpo del texto en el que se desarrolla la noticia también es un indicador que los marca pragmáticamente. En términos de flujo de información, los titulares adelantan el tema o los temas que serán desarrollados en la nota periodística.

Los titulares de prensa condensan la noticia al presentar el punto nodal en una corta frase e incluso en una sola palabra que llega a constituir un verda-

dero resumen del acontecimiento. Decir lo más que se pueda en el menor número de palabras posible es la fórmula comunicativa que los rige. Para cumplir esta consigna, los redactores de titulares explotan al máximo todos los recursos que el lenguaje permite: elisiones, anáforas, metáforas, discurso citado, etcétera. Por estas características, los titulares de prensa constituyen un lugar privilegiado para observar ciertos fenómenos lingüísticos de índole sintáctica —orden de palabras, por ejemplo_-, semántica — la red de sentidos sociales, políticos y culturales que está en juego-y pragmática -implicaciones, intertextualidad y polifonía-. Los encabezados analizados se componen de dos partes, que se distinguen por la tipografía y el espacio que ocupan. La parte principal, el titular propiamente dicho, se codifica en un tipo de letra de tamaño mayor y estilo diferente, que en ocasiones se imprime en color. La parte secundaria, el o los subtitulares, se codifica en una letra de tamaño menor - pero mayor al cuerpo del texto-, suele destacarse mediante un estilo específico y ocasionalmente también aparece en color. En el periodismo actual, el uso tipográfico considera varios tipos de subtitulares: antetítulo, sumario, subtítulo, interludio o ladillo (Martínez, 1974: 161-162). O bien se habla de cintillo, sobretítulo (Rivadeneira, 1980: 156), balazos, llamadas, etcétera. Esta caracterización basta para los fines del presente trabajo, pero estamos conscientes de que no es sólo cuestión de tipografía lo que distingue a uno de otro. Por ejemplo, podemos referirnos brevemente a las clases de titulares que Armentia y Caminos (2003: 73) definen a partir de sus características gramaticales: expresivos, apelativos, informativos o de actos de habla.

\section{TÓPICOS Y SUBTÓPICOS: URDIMBRES Y TRAMAS DE SUTILES TEJIDOS}

En tanto un discurso no se conforma de un solo tema o asunto sino más bien de una secuencia de temas que se relacionan entre sí, en el encabezado de prensa es común distinguir una serie de unidades que resumen esta trama. ${ }^{6}$ Esencialmente, los titulares de prensa construyen su sentido a partir de la dimensión pragmática en la que se basan la información o las opiniones, en atención a la preconcepción de los que se suponen lectores asiduos o constantes del medio. Esta dimensión pragmática determina el tópico principal al que se ligan los subtópicos. Esta simple operación es una dimensión discursiva en sí misma, el grado de prominencia que se confiere a los distintos temas en el conjunto del encabezado y la relación que se establece entre ellos implica la construcción de la escena discursiva que expone la noticia. En los titulares de prensa suele distinguirse entre el tópico principal y los subtópicos relacionados con aquél mediante dos mecanismos: cada tema se codifica en una frase u oración - aunque también se da el caso de que en éstas se introduzca más de un tema- y con tipografía distinta.

\footnotetext{
${ }^{6}$ En términos de van Dijk (1980: 43; 1990: 83) podemos hablar de macroestructura semántica del discurso.
} 


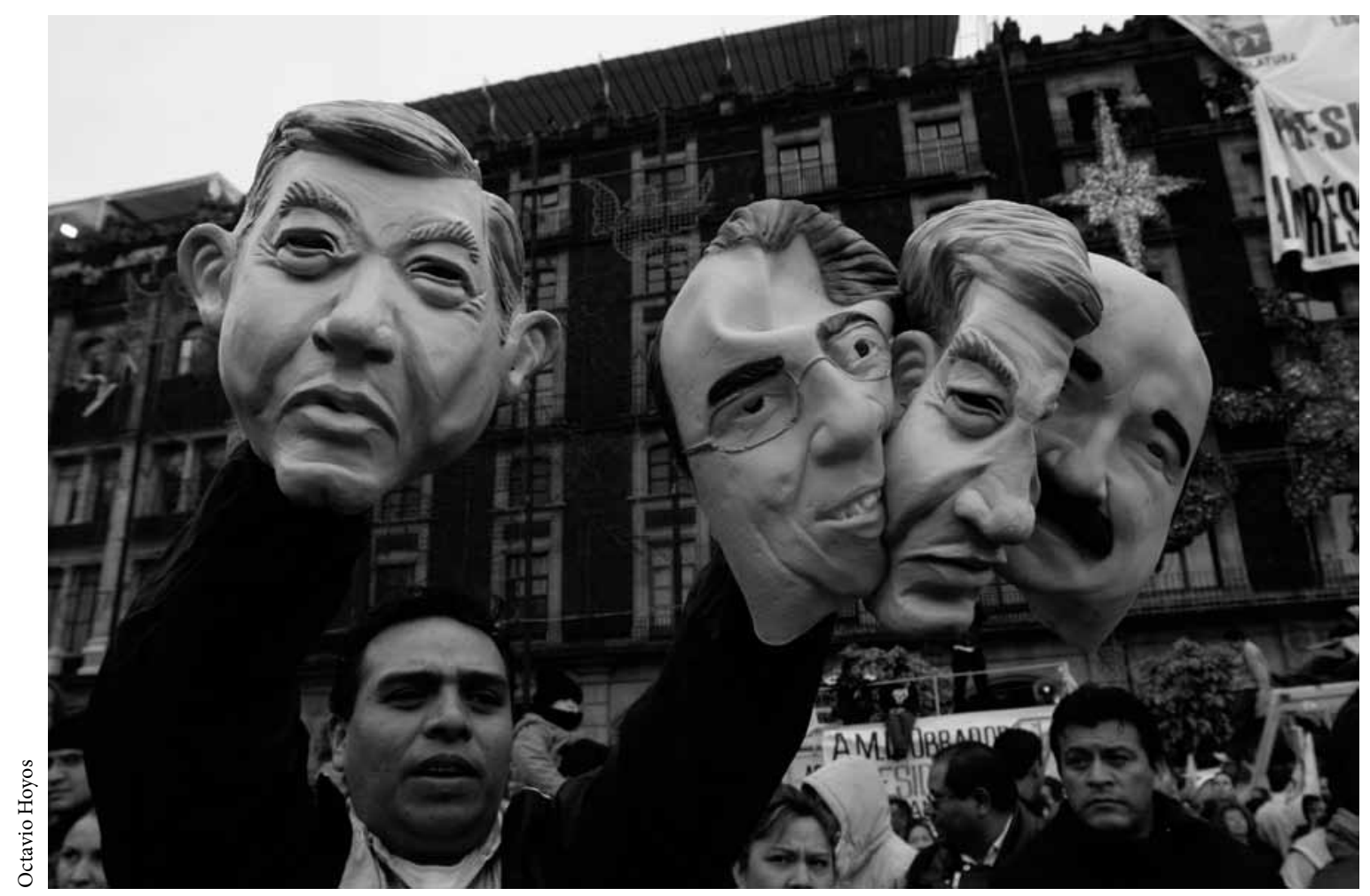

Simpatizantes de Andrés Manuel López Obrador, 2005.

En los titulares del 25 de abril de 2005 la prensa mexicana destacaba dos grandes temas en los que reconocía a los protagonistas más visibles del evento del día anterior: la marcha y Andrés Manuel López Obrador. El primero, un protagonista colectivo conformado por los cientos de miles de personas que se habían dado cita en el centro de la ciudad de México para manifestarse pacíficamente. En relación con la marcha, los titulares de prensa destacaban tres temas: el número de participantes, el objetivo de la movilización y el reconocimiento individual de algunos de los manifestantes. El segundo, un protagonista individual, que encarnaba el motivo de la manifestación ciudadana, un turbio proceso de desafuero al que López Obrador había sido sometido durante meses, respecto del cual se aludía a tres temas: su retorno a la jefatura de Gobierno del Distrito Federal, el lanzamiento de facto de su candidatura para contender como candidato del Partido de la Revolución Democrática a la presidencia de la república en las elecciones de 2006 y su actitud ante el enrarecido clima político que en esos momentos se vivía en el país.

Las posibilidades de combinación que se observan entre el tópico principal establecido y los subtópicos reconocidos en los encabezados permiten a cada periódico tejer de manera particular un sutil entramado discursivo que exhibe el punto de vista desde el cual relata el suceso y muestra la posición editorial de cada uno de los rotativos. Los titulares de primera plana, la unidad de análisis que hemos elegido, se constituyen por más de una frase u oración. Para fines de este trabajo nos será útil distinguir dos momentos: en el primero nos circunscribimos al análisis de las frases y las oraciones que contienen los tópicos reconocidos como principales y que la 
prensa destaca utilizando un formato tipográfico mayor dentro del mismo titular; en un segundo momento consideramos el conjunto de tópicos y subtópicos que se registran en los 15 titulares.

\section{Urdimbres}

El análisis de los tópicos principales en sí mismos es interesante, ya que representan una especie de urdimbre o primer hilo que guiará el tejido discursivo. Los tópicos principales pueden verse como los puntos de referencia en relación con los cuales se disponen los subtópicos. La tabla 2 muestra los 15 títulos que se destacaron con mayor formato en los encabezados de la prensa nacional del 25 de abril de 2005. Como puede observarse, se trata de frases $\mathrm{u}$ oraciones cortas en las que se enuncia un solo tópico, con excepción de Reforma y Milenio Diario, que conjugan dos tópicos en la misma oración.

El tema de la marcha no fue el más recurrente, sino AMLO. De los 15 titulares analizados, 13 - incisos $a$ al $m$ - destacan la figura de López Obrador como el tema principal, lo que representa $86.7 \%$ del total. El tema de la marcha se menciona sólo en dos titulares - n y o-, lo que constituye sólo $13.3 \%$. De acuerdo con lo anterior, podemos decir que el gran tema fue la persona que logró convocar a cientos de miles en el Zócalo capitalino y no la ciudadanía que se volcó a las calles para manifestar su descontento.

Los titulares constituyen un conjunto diverso en cuanto a su forma. Se observa una gama que va desde los enunciados de una sola palabra hasta los que despliegan una oración completa. En el primero de los casos tenemos el encabezado "Autodestape" ( $\mathrm{La}$ Crisis) que es un simple y llano sustantivo, sin otro elemento que lo determine o lo modifique. Pero lo simple y lo llano de este titular es sólo formal, ya que se relaciona con un campo clave en la tradición política que ha prevalecido a lo largo de décadas en nuestro país: el llamado "tapado" y con él el acto de
Tabla 2. Encabezados principales publicados el 25 de abril de 2005

\begin{tabular}{l}
\hline ¡VUELVE! (La Prensa) \\
\hline López Retador: Reasumirá hoy (Excélsior) \\
\hline Pide López Obrador detener encono (El Universal) \\
\hline Plantea AMLo pacto de unidad (El Sol de México) \\
\hline Llama AMLO a poner fin al encono (Milenio Diario) \\
\hline $\begin{array}{l}\text { Discurso conciliador de AMLO; ofrece no volver al } \\
\text { estatismo (El Financiero) }\end{array}$ \\
\hline Conciliador, PIDE PACTo (Impacto El Diario) \\
\hline Sin cargos, con recursos públicos, AMLo arranca \\
(La Crónica de Hoy) \\
\hline ¡Arranca! (El Gráfico) \\
\hline Autodestape (La Crisis) \\
\hline $\begin{array}{l}\text { AMLo informó de su proyecto de gobierno } \\
\text { (Diario Monitor) }\end{array}$ \\
\hline MUEve Tropas (Metro) \\
\hline Moviliza 'tropas' y regresa al GDF (Reforma) \\
\hline Rompen el silencio (El M) \\
\hline $\begin{array}{l}\text { Más de un millón repudiaron el abuso del poder } \\
\text { (La Jornada) }\end{array}$ \\
\hline
\end{tabular}

destaparlo, el "destape", y un posible "autodestape" alude a una práctica cultural mexicana instaurada durante las décadas priistas, de elegir -o mejor dicho designar- y dar a conocer a la opinión pública al candidato a la presidencia de la república. Este titular apela a un conjunto de significados asociados a una palabra que sólo es posible recuperar si se conoce la práctica cultural a la que se asocia, pues a fin de cuentas todo discurso "forma parte de una historia de discursos: todo discurso es la continuación de discursos anteriores, la cita explícita o implícita de textos previos" (Reyes, 1984: 42). El encabezado de La Jornada - "Más de un millón repudiaron el abuso del poder" -, por otro lado, fue el único de todo el conjunto que explícitamente da a los ciudadanos movilizados un carácter de sujetos, si bien no los nombra explícitamente y recurre a una forma nominal que, por medio del adverbio de cantidad y un numeral explícito -más de un millón-, los destaca por 
su cantidad sin encasillarlos en alguna categoría social o política específica.

Centremos nuestra atención en el tema menos recurrente, la marcha. Los cuatro titulares en donde se le menciona como tópico se reproducen en la tabla 3. Todo el conjunto muestra oraciones con un alto grado de transitividad (Hopper y Thompson, 1980) en las que se reconoce un sujeto agentivo revestido de animacidad y volición. Como podemos observar, la marcha, o mejor dicho los marchistas -los hombres y mujeres que realizaron la marchase mencionan en estos cuatro titulares, aunque no en todos de la misma manera. Las menciones de los asistentes a la marcha en $3 a$ y $3 b$ correspondientes a los periódicos Milenio Diario y Reforma, respectivamente, contrastan con aquellas que se registran en $3 c$ y $3 d$ y que corresponden a El M y La Jornada. En $3 a$ y $3 b$ el sujeto es una tercera persona singular que el contexto permite entender como AMLO. En ambos enunciados los marchistas se encuentran codificados como un objeto altamente afectado. En $3 c$ y $3 d$ los marchistas desempeñan la función de sujeto; sin embargo, sólo en $3 d$ aparecen como sujeto explícito que se expresa mediante una frase nominal cuantitativa: "más de un millón" [de personas].

El encabezado de $E l M$, "Rompen el silencio", deja el sujeto tácito - una tercera persona del plural "ellos"-, lo que tiene el efecto de centrar nuestra atención en el acto mismo que fue realizado. El titular encierra una paradoja: con su asistencia, las personas convocadas a la "Marcha del Silencio" rompen precisamente el silencio. El silencio que rompe el silencio, el silencio que manifiesta un desacuerdo y no una complicidad, el silencio como recurso para exigir ser escuchado. Otra lectura posible es que este titular constituye una crítica a los participantes en la marcha, incapaces de seguir hasta sus propias reglas: rompen el silencio de su "Marcha del Silencio".

El titular de La Jornada, $3 d$, "Más de un millón repudiaron el abuso del poder", comparte parcialmente la misma perspectiva. Por una parte, el sujeto se encuentra codificado por una frase cuantitativa que pone de relieve la gran cantidad de participantes
Tabla 3. Encabezados en los que se menciona el tema de la marcha

a) Mueve tropas (Milenio Diario)

b) Moviliza 'tropas' y regresa al GDF (Reforma)

c) Rompen el silencio (el $M$ )

d) Más de un millón repudiaron el abuso del poder (La Jornada)

que asistieron a la marcha. Por otra parte, el verbo elegido, "repudiar", alude a un acto de rechazo, no aceptación del objeto, en este caso "el abuso del poder"; aludir a un abuso del poder en forma definida implica que tal abuso es de todos conocido, que existe alguien que ejerce tal abuso del poder y por ende que se repudia también a éste.

Las oraciones en $3 a$ y $3 b$ son muy similares, en ambas se usan verbos semejantes, "mover" y movilizar", y se alude al mismo objeto: las "tropas". Esta similitud no parece casual, ya que los periódicos a los que corresponden, Metro y Reforma, pertenecen a la misma casa editorial. En contraste con los dos titulares anteriores, en éstos los participantes en la marcha son tratados como objetos pacientes. Objetos que son "movilizados" por un sujeto activo que en este contexto resulta fácilmente recuperable, se trata, ni más ni menos, que del convocante a la marcha: Andrés Manuel López Obrador.

La selección léxica que acompaña estos dos titulares es, curiosamente, la misma y no resulta gratuita. Los participantes de la marcha son denominados, en ambos casos, "tropas". Nuevamente estamos ante una palabra clave que dispara un proceso asociativo específico. Cabe recordar, como señala Lyons, que "una palabra no puede entenderse en su totalidad independientemente de otras palabras relacionadas con ella y que delimitan su sentido" (Lyons, 1981: 81). Así, el sustantivo seleccionado remite al ámbito de lo militar, el ejército como una institución altamente jerárquica, a la obediencia que deben los subordinados a sus mandos, en quienes reconocen el poder de disponer de ellos, de movilizarlos. Las implicaciones que tiene el término "tropas" para aludir 
Tabla 4. Encabezados que tienen a López Obrador como sujeto

a) ¡Vuelve! (La Prensa)

b) López Retador: Reasumirá hoy (Excélsior)

c) Moviliza 'tropas' y regresa al GDF (Reforma)

a los marchistas pueden ser bien calculadas: el actor responsable de la movilización puede presentarse entonces como un personaje autoritario que ejerce su poder castrense sobre una masa, grupo o muchedumbre que lo obedece. No está por demás reflexionar sobre las frecuentes atribuciones negativas de "autoritario" que este personaje político ha recibido en los últimos años, y que alcanzarían su grado máximo en la campaña negra del polarizado proceso electoral de 2006, de cuyas heridas aún se restaña la sociedad.

Los titulares que aluden a Andrés Manuel López Obrador como tema principal varían en cuanto al tema que destacan en relación con éste: su retorno a la jefatura de Gobierno del Distrito Federal, la actihabía sido objeto por parte del gobierno federal, el inicio de facto de su candidatura a la presidencia de la república en 2006 y su poder de convocatoria presentada como un acto de autoritarismo. Veamos un poco más de cerca cada uno de estos subgrupos. El retorno se presenta cada vez de una manera diferente. En la tabla 4 reproducimos los tres titulares que refieren a este tema.

En $4 a$ estamos ante un enunciado exclamativo reducido a su mínima expresión, el verbo conjugado en tercera persona singular en presente de indicativo. Ni el actor ni la meta que exige la estructura argumental del verbo "volver" están explícitos, el hablante - en este caso los redactores del titularapela al hecho de que su recuperación es posible en el contexto en el que se produce la noticia: todo el mundo sabía entonces que se estaba refiriendo a Andrés Manuel López Obrador, quien anunciaba su retorno a la jefatura del GDF. El modo exclamativo en el que se enuncia la noticia implica que de algún modo dicha noticia causa asombro o temor.

En $4 b$ el tema del retorno se enuncia de manera peculiar con la frase "López Retador", que antecede al predicado "Reasumirá hoy". Tanto la tipografía elegida como la puntuación permiten un juego interesante. En primer lugar "López Retador" apela a la cercanía fonológica con "López Obrador” para deslizar sutilmente un calificativo que pretende delinear una actitud desafiante y provocativa del personaje, $y$ el uso de las mayúsculas en cada palabra de la frase, emulando la convención ortográfica para los nombres propios, indica que el autor espera que ésta sea la lectura de su público. Los dos puntos que separan esta frase del predicado juegan un doble papel: por una parte la separan de él confiriéndole una autonomía relativa, se trata de una unidad informativa en sí misma; por la otra, permite que al encontrarse antes del predicado, en una cierta lectura pueda ocupar el lugar del sujeto ausente en aquél. De cualquier manera, la posición primera que ocupa esta frase implica poner en relieve la actitud — retadora- del sujeto.

El tema de la candidatura, presente en cuatro titulares, también aparece cada vez de manera diferente. En la tabla 5 se pueden observar los titulares relacionados con este tema. En tres de las cuatro oraciones $-5 a, 5 b$ y $5 c-$ se alude a un inicio de facto de la campaña por la presidencia de la república para 2006 en términos de la práctica priista vigente hasta el 2000. En $5 c$ se utiliza el término "autodestape", del que ya hemos hablado. En $5 a$ y $5 b$ se usa el verbo "arrancar", que se asocia a la "carrera presidencial”. El $5 b$ no deja lugar a dudas de estar ante una expresión hípica que ubica al conjunto de los "presidenciables" en un ámbito fuertemente competitivo. La tradición política mexicana, en buena parte forjada en época priista, alude a ellos como "caballada", que puede estar, según la época, más o menos "flaca".

En $5 a$ dos frases anteceden la oración principal indicando las circunstancias en las cuales se produce la acción de arrancar: "sin cargos, con recursos públicos". La primera anuncia un camino despejado - aunque no se especifica nada más-, la segunda asume el uso - reprobable-de los recursos públicos 
Tabla 5. Encabezados que se refieren a la candidatura de AMLO

a) Sin cargos, con recursos públicos, AMLO arranca (La Crónica de Hoy)

b) ¡Arranca! (El Gráfico)

c) Autodestape (La Crisis)

d) AMLO informó de su proyecto de gobierno (Diario de México)

en beneficio del postulante. El enunciado en $5 d$ se aparta de los otros tres: "AMLO informó de su proyecto de gobierno". Si bien puede ser agrupado con aquellos que presentan el tema de la candidatura presidencial, no se ocupa del inicio de la candidatura, más bien se enfoca en el hecho de que el sujeto tiene un "proyecto de gobierno" del cual informó a los asistentes a la marcha.

El tema de la actitud conciliadora mostrada por AMLo fue el que apareció con más frecuencia en los titulares de la prensa mexicana. En la tabla 6 se presentan los cinco enunciados con este tema. Dicha actitud se manifiesta en el llamado a detener el encono y el planteamiento de un pacto de unidad. El hecho de que éste fuera el tema destacado con mayor recurrencia en los titulares es un indicador de que esta actitud llamó fuertemente la atención de los reporteros porque era poco esperada. La noticia fue que AMLO no respondiera a tal encono con un llamado a los asistentes a la marcha para resistir de manera violenta al embate del que estaba siendo objeto por parte del gobierno federal.

\section{Tramas}

El tejido discursivo de los encabezados cuya urdimbre fue puesta en relieve mediante los tópicos establecidos en los titulares se completa con los subtópicos que se enuncian en lo que podemos llamar de manera genérica los subtitulares - según el formato establecido por cada periódico pueden presentarse tipográficamente como antetítulo, subtítulo, balazo, llamada, etc.-, para configurar así una peculiar trama discursiva que da cuenta de una perspectiva que distingue en buena medida la casa editorial que la produce. Realmente los temas que se enuncian como subtópicos siguen siendo los mismos que antes se presentaron como tópicos: la marcha y Andrés Manuel López Obrador. En relación con este último se destaca su retorno a la jefatura de Gobierno del Distrito Federal, el lanzamiento de facto de su candidatura por la presidencia de la república o su actitud ante el enrarecido clima político que entonces se vivía. Sin embargo, lo que se jerarquiza como tópico y como subtópico varían en cada periódico, lo que constituye en sí mismo un microdiscurso.

El análisis de cómo se teje esta trama discursiva nos permite observar la construcción de la noticia en cada periódico: la relevancia que se otorga a algunos temas al reconocerlos como tópicos, colocar otros como trasfondo esbozado por los subtópicos y omitir otros. A partir de la comparación entre titulares y subtitulares (véase tabla 1) surgen interesantes hallazgos. La gran mayoría de los periódicos -13 de los 15 , lo que representa $86.6 \%$ del totalconsignó más de un tema entre títulos y subtítulos; sin embargo, no todos lo hicieron en la misma proporción. Ocho de los 15 titulares consignaron tres de los cuatro temas, 53.3\% del total: La Prensa, Excélsior, El Universal, Impacto El Diario, La Crónica de Hoy, Reforma, El M y La Jornada. Tres rotativos registraron sólo dos temas, es decir, 20\%: El Sol de México, Milenio Diario y El Gráfico. Otros tres: El Financiero, La Crisis y Metro, se concentraron en un solo tema. Sólo uno, Diario de México, tocó los cuatro temas. Como podemos observar, La Prensa da relevancia al lanzamiento de facto de la candidatura de López Obrador y deja como trasfondo la actitud conciliadora de éste ante el embate federal, la magnitud de la marcha y su retorno a la jefatura del Distrito Federal: 


\section{¡VUELVE!}

Desde esta madrugada López Obrador regresó a trabajar en su oficina; logra reunir a miles en Marcha del Silencio / Propone un pacto sin revanchismos / Cuauhtémoc sí participó / Todos lo quieren desaforadamente / Saldo blanco en la concentración / No odiamos ni buscamos venganzas (La Prensa).

A pesar de que los titulares de El Financiero, $\mathrm{La}$ Crisis y Metro se centran en la figura de López Obrador, ninguno coincide en el tema que destaca. Mientras que El Financiero registra la actitud de AMLO - "Discurso conciliador de AMLO; ofrece no volver al estatismo"-, La Crisis se enfoca en el inicio de facto de su candidatura presidencial - "Autodestape"-, en tanto que Metro destaca su capacidad de convocatoria, misma que codifica como poder de mando - "MUeve tropas"- Tanto El Sol de México como Milenio Diario resaltaron la actitud pacífica de AMLO, pero la trama discursiva que desarrollan es distinta. El primero apunta básicamente hacia la actitud conciliadora y sólo en uno

\section{Plantea AMLO pacto de unidad}

Llama a unificar el país "de manera menos conflictiva"; el apoyo popular no basta, reconoce / Pide no temer a su proyecto de izquierda; "no odiamos ni buscamos venganza" / Exhorta a sus adversarios a deponer el encono y anuncia plan de Gobierno ante miles de marchistas (El Sol de México).

Milenio Diario, si bien presenta el tema de la actitud conciliadora como título principal, teje un discurso que pone en relieve distintos aspectos de la marcha:

\section{Llama AMLO a poner fin al encono}

Marcharon al Zócalo cientos de miles / "Sufragio efectivo, no descalificación" / Movilizaciones en París, Barcelona, Madrid, Nueva York, Washington, Sydney, Quebec y Copacabana (Milenio Diario).

Por su parte, El Gráfico destaca el inicio de la candidatura presidencial y sólo de pasada plantea el tema

del retorno a la jefatura de Gobierno del Distrito Federal, aunque hace concurrir mediante un discurso directo a un actor político - la Procuraduría General de la República - que sanciona tal posibilidad - "será un delito"—.

\section{¡Arranca!}

López Obrador olvida desafuero; delinea su proyecto basado en combate a la pobreza / Hoy regresa al GDF; será un delito: PGR (El Gráfico).

A diferencia de lo que sucede cuando nos concentramos sólo en los títulos, al observar la trama de los titulares constatamos que el tema más recurrente fue la "Marcha del Silencio" a la que se hace referencia, de una u otra manera, en 13 de los 15 titulares, lo que representa $83.3 \%$. El segundo tema más recurrente fue la actitud conciliadora de AMLO, con 11 citas $-73.3 \%$ - El retorno a la jefatura de Gobierno se consigna en nueve titulares - $60 \%$ - en tanto que el tema de la candidatura aparece sólo en seis - 40\%-.

Además de que el dato cuantitativo habla por sí mismo, también resulta interesante observar cómo se alude a la marcha. El aspecto más destacado en relación con la marcha fue la cantidad de participantes. De los 12 diarios que mencionaron el acontecimiento, únicamente La Crónica de Hoy y El M no se ocuparon de este tema en sus titulares. En los 10 rotativos restantes el reconocimiento del número de asistentes va desde un indefinido "miles" $-\mathrm{La}$ Prensa, El Sol de México y Metro-, pasando por "cientos de miles" - Excélsior, Milenio Diario, Impacto El Diario, Diario de México y Reforma- hasta un

Tabla 6. Encabezados que se refieren a la actitud de AMLO
a) Pide López Obrador detener encono (El Universal)
b) Plantea amlo pacto de unidad (El Sol de México)
c) Llama AMLO a poner fin al encono (Milenio Diario)
d) Discurso conciliador de AMLO; ofrece no volver al estatismo (El Financiero)
e) Conciliador, PIDE PACTo (Impacto El Diario) 
apabullante "más de un millón" — La Jornada-. El Universal, Impacto El Diario y Metro hablan de la discrepancia entre el número de asistentes reconocido por el gobierno federal y el capitalino a través de sus respectivas secretarías de Seguridad Pública:

1 millón 200 mil, según ssp capitalina. 120 mil participantes, reportó la ssp federal. Mil 699 elementos vigilaron el trayecto (El Universal).

SSPF 120 mil. SSPDF millón 200 mil. Organizadores millón 300 mil (Impacto El Diario).

Reporta el GDF 1 millón de personas: son 120 mil, dice el Gobierno Federal (Metro).

En este contexto, llama la atención el titular de $\mathrm{La}$ Crónica de Hoy, que se aparta de los otros rotativos por su insistencia en el uso de los recursos materiales y humanos del Gobierno del Distrito Federal, que según este diario fueron utilizados en la organización y realización de la marcha:

Empleados de Atención Ciudadana del gobierno capitalino hicieron vallas / Policías efectuaron tareas de franeleros / Trasladaron autobuses públicos a viejitos / Usaron helicóptero de ssp con fines propagandísticos (La Crónica de Hoy).

La Prensa se aparta del resto de los diarios analizados al presentar dos temas que ningún otro periódico consigna en sus titulares. Por un lado habla de un "Saldo blanco en la concentración", lo cual implica que se esperaban manifestaciones de violencia en la marcha, y por otro recoge una expresión acuñada en la marcha: "Todos lo quieren desaforadamente". Milenio Diario también representa un caso que podría considerarse sui generis por ser el único periódico que destacó en su titular la solidaridad internacional que recibieron los manifestantes: "Movilizaciones en París, Barcelona, Madrid, Nueva York, Washington, Sydney, Quebec y Copacabana". Otro tema recurrente en los titulares de prensa de ese día es el que refiere a la actitud de los asistentes.
La Jornada, El Universal y Milenio Diario reconocieron que los participantes en la marcha se manifestaron contra la política desplegada por el gobierno federal.

Más de un millón repudiaron el abuso del poder ( $L a$ Jornada).

Cientos de Miles vs. Desafuero (Excélsior).

"Sufragio efectivo, no descalificación" (Milenio Diario).

Marcha que se resistió al silencio (El Universal).

Rompen el silencio. La marcha convocada por AMLO para protestar por el desafuero se convirtió en un mitin de apoyo político-electoral $(E l M)$.

Las formas lingüísticas y la selección léxica de los verbos utilizados en estos titulares y subtitulares son significativas. Los tres primeros aluden, aunque de manera distinta, al objetivo que animaba la marcha: el rechazo al proceso de desafuero. La Jornada fue el único rotativo que en su titular principal expresó explícitamente el tema, para ello utilizó el verbo "repudiar". Excélsior optó por una forma latina ampliamente utilizada para expresar la relación de oposición: "Cientos de Miles vs. Desafuero". Milenio Diario introduce una cita directa que recoge una de las consignas que se dejaron oír en la marcha: "Sufragio efectivo, no descalificación", actualización del lema de campaña de Francisco I. Madero contra una nueva reelección de Porfirio Díaz: "Sufragio efectivo, no reelección". Esta frase constituye un doble reclamo al gobierno federal, expresado en dos partes: la primera es una forma afirmativa que manifiesta el requerimiento de que el gobierno federal respete la voluntad emitida por los ciudadanos mediante el voto, la segunda parte presenta una forma negativa mediante la cual la sociedad civil participante en la marcha pedía al gobierno federal parar la campaña de descalificación hacia AMLO y reconocer su derecho a contender por la presidencia de la república. 
Los otros dos periódicos que trataron el tema en sus titulares de primera plana se centraron en el tema del silencio, la modalidad que los organizadores del evento habían marcado para el desarrollo de la marcha. El Universal condensó el espíritu de la marcha en una frase: "Marcha que resistió al silencio", para aludir a la aparente paradoja del hecho de que una manifestación silenciosa pudiera constituirse en un acto explícito de resistencia y con ello el reconocimiento de que el silencio también significa. Muy cercana a esta forma está la frase utilizada por El M: "Rompen el silencio". Con el uso del verbo "romper" el titular de este diario destaca únicamente el acto de irrupción y deja fuera la resistencia. El subtitular que acompaña esta frase deja clara la posición del periódico: una marcha cuyo fin era protestar por el desafuero se convirtió en un mitin de apoyo político-electoral. En este contexto, "rompen el silencio" implica no la protesta contra el desafuero, sino el pronunciamiento por la candidatura de AMLO.

La marcha fue codificada como un colectivo, como una masa cuya principal cualidad fue su carácter multitudinario, haber estado integrada por un gran número de participantes. "Marcha", usado tres veces, $y$ "cientos de miles", en cinco ocasiones, fueron las formas más utilizadas para referirse a la movilización. El actor más destacado fue, desde luego, Andrés Manuel López Obrador, quien de manera frecuente aparece codificado por su acrónimo o bien por sus apellidos. La tabla 7 muestra las formas como fue nombrado por los periódicos en sus ediciones del 25 de abril de 2005.

Sólo dos periódicos se apartan de este uso: el Excélsior $(7 b)$-en cuyo titular se hace el juego de palabras "López Retador" al que aludimos en párrafos anteriores y que en un subtitular abre una cita directa en la que una "viejita" le nombra simplemente "Andrés" - y La Crónica de Hoy (7h) — se observa una variación interesante: mientras que en el titular se hace referencia al personaje como AMLO, en uno de los subtitulares se utiliza solamente el primer apellido "López" - . Esta última práctica, recuérdese, sería empleada durante la campaña presidencial de
2006 para referirse de manera peyorativa a este personaje. Precisamente La Crónica de Hoy fue el diario que introdujo en el clima informativo la tradición de referirse a este personaje sólo como "López" en una estrategia de descalificación de imagen cuyo uso se expandiría a otros medios y estaría presente en el discurso de algunos funcionarios del gobierno federal, como el vocero del gobierno foxista, Rubén Aguilar. En El M $(7 \mathrm{~m})$ también se advierte una variación, en este caso, entre el uso del acrónimo y la referencia mediante los apellidos. En relación con López Obrador como actor, es interesante además observar la forma en que se codificó su participación en la marcha:

(AMLO) ante miles de marchistas (El Sol de México).

López Obrador en marcha multitudinaria (Impacto El Diario).

Marchan miles con AMLO (Metro).

Marchan cientos de miles por AMLO (Reforma).

En cada uno de los titulares se utilizan distintas preposiciones. Podemos distinguir dos grupos: el que describe la posición de AMLO respecto de la marcha -El Sol de México e Impacto El Diario- y el que se ocupa de los participantes en la misma y su relación con AMLo - Metro y Reforma-. Así, en el titular de El Sol de México, es posible verlo "ante miles de marchistas", hablando frente a las miles y miles de personas congregadas ese día en el Zócalo capitalino. Cabe advertir que este titular fue uno de los que destacaron como tema casi único la actitud conciliadora de AMLo. El titular de Impacto El Diario, en contraste, lo presenta como un participante más en la marcha, aunque lo suficientemente destacado para merecer una mención particular. En el segundo grupo se ubican los participantes en la marcha: Metro utiliza la preposición con que confiere a la relación un sentido comitativo, los participantes acompañan a AMLO, machan a su lado, marchan con él; Reforma, por su parte, prefirió presentar esta relación como un acto de proselitismo, los asistentes marcharon en pro de AMLO, a favor de él. Fuera de 
Tabla 7. Cómo se nombró a López Obrador en los encabezados

a) Desde esta madrugada López Obrador regresó a trabajar en su oficina (La Prensa)

b) López Retador: Reasumirá hoy “¡Ay, Andrés! Ni aquí cumples...” y tiró la flor al suelo (Excélsior)

c) Pide López Obrador detener encono (El Universal)

d) Plantea AмLо pacto de unidad (El Sol de México)

e) Llama AмLo a poner fin al encono (Milenio Diario)

f) Discurso conciliador de AMLo (El Financiero)

g) López Obrador en marcha multitudinaria (Impacto El Diario)

h) Sin cargos, con recursos públicos, AMLO arranca López regresa hoy a su oficina: "sigo siendo el jefe de GDF" (La Crónica de Hoy)

i) López Obrador olvida desafuero (El Gráfico)

j) AMLo informó de su proyecto de gobierno (Diario de México)

k) Marchan miles con AMLO (Metro)

l) Marchan cientos de miles por AмLо (Reforma)

m) La marcha convocada por AMLO para protestar por el desafuero se convirtió en un mitin de apoyo políticoelectoral / Con miras al 2006 detalla López Obrador su proyecto alternativo de nación y llama a crear un pacto social para realizar cambios en el país $(E l M)$

n) AMLO: miedo irracional al proyecto alternativo de país / El gobernante regresa hoy al GDF a "supervisar obras y programas" (La Jornada)

Andrés Manuel López Obrador, el reconocimiento de la participación de otros actores individuales fue escaso. Los únicos personajes destacados en los titulares fueron Cuauhtémoc Cárdenas, Porfirio Muñoz Ledo, Yeidckol Polevnsky y los hijos de AmLO:

Cuauhtémoc sí participó (La Prensa).

Muñoz Ledo afirmó que la democracia está en peligro. Fue abucheado (Impacto El Diario).

López Obrador marchó al zócalo acompañado de Yeidckol Polevnsky y sus hijos (Metro).

Estos actores destacan por diferentes causas. Se había hablado ampliamente sobre el distanciamiento entre López Obrador y Cuauhtémoc Cárdenas, reconocido como el "líder moral" del PRD y candidato a la presidencia de la república de este partido por cuatro ocasiones, y se especuló mucho sobre su participación en la marcha. La Prensa afirma fehacientemente en su encabezado que Cárdenas sí había participado, lo que implica que se esperaba lo contrario. El titular de Impacto El Diario hace referencia a Porfirio Muñoz Ledo, quien fundó el PRD con Cárdenas. Por último, el titular de Metro hace notar la participación de actores cercanos a los afectos de AMLO: Jeidckol Polevnsky y sus hijos. Polevnsky, además, de extracción empresarial, acababa de contender como candidata del PRD en el Estado de México: mujer, empresaria, militante reciente y cercana en sentido político y personal a AMLO.

\section{VOCES Y SILENCIOS. UN JUEGO DE LUCES Y SOMBRAS}

Como hemos mostrado hasta aquí, el tejido discursivo de los titulares es un fenómeno a todas luces dinámico, lo que cuenta como tópico o subtópico no está determinado por el hecho mismo y varía de periódico a periódico. El acontecimiento es reconstruido por la escena discursiva que muestra a los actores y las acciones que en él intervienen. Sin 
embargo, cada periódico construye su propia escena discursiva, expone el acontecimiento desde una perspectiva diferente desde la cual se iluminan de manera preferente uno o varios actores y sus acciones. El efecto que se produce es distinto y en ocasiones francamente opuesto.

En los titulares de prensa actores y acciones son enunciados como tópicos o temas, la relativa importancia que se reconoce a unos y otros se manifiesta mediante la distinción entre tópicos y subtópicos. Así, un actor al que se le confiere la máxima importancia aparecerá codificado como tópico, en tanto que los otros se expresarán como subtópicos. Lo mismo vale para la o las acciones que, desde la perspectiva adoptada por un periódico, son centrales al acontecimiento: se expresarán como tópicos y las demás serán relegadas en un segundo plano en calidad de subtópicos. En el caso que nos ocupa, si bien los temas son constantes - podríamos decir que forman un conjunto cerrado- en todos los periódi$\cos$, lo que se reconoce como tópico o subtópico varía de un periódico a otro. Esto permite construir diversas texturas discursivas. En los titulares del 25 de abril de 2005 se observa una clara tendencia a dar mayor relevancia a la figura de AMLO que a los participantes de la marcha. Como se puede advertir en la tabla 8, Andrés Manuel López Obrador apareció como tópico, es decir, mediante un proceso de grounding (Wårvik, 1996), AMLO fue presentado como el actor más prominente del acontecimiento, en tanto que los participantes en la marcha y sus acciones fueron codificados como subtópicos, es decir, como el background o trasfondo que enmarcó al actor principal.

Es claro que esto tiene que ver con el hecho de que Andrés Manuel López Obrador es identificado como el nombre propio de una persona individual, lo que lo hace prototípico candidato a sujeto: más humano y animado, más volitivo, más contable. En los titulares de prensa que se analizaron AMLO aparece siempre codificado como sujeto activo que regresa a la oficina de gobierno, reúne a miles de personas, propone, plantea, o pide pacto, llama a deponer el encono y a unificar el país, pide no temer a su proyecto, exhorta a sus adversarios, ofrece no volver al estatismo, arranca su campaña por la presidencia, informa de su proyecto de gobierno, marcha al Zócalo y moviliza tropas.

Los participantes de la marcha se diluyen en el anonimato, no obstante que son seres humanos contables. En los titulares de prensa son tratados como un conjunto genérico e indefinido, casi como una masa. Se les contabiliza y se habla del número de personas, variable según la fuente, que asistieron al evento. A diferencia de lo que sucede con AMLO, los participantes en la marcha son codificados en la mayor parte de los encabezados como sujetos $(8 a$, $8 b, 8 e, 8 h, 8 i, 8 j, 8 k)$, aunque también como objetos $(8 a, 8 f, 8 h, 8 i)$, e incluso como oblicuos $(8 d, 8 f)$.

Sin embargo, cuando los participantes de la marcha son codificados como sujetos despliegan una menor gama de actividades que las atribuidas a AMLO. La actividad que más recurrentemente se destaca en los titulares de prensa respecto de los miles o cientos de miles de personas es el hecho de que marcharon, es decir, que participaron en la marcha $(8 e, 8 h$ y $8 i)$. Otras actividades que desarrollaron fueron: resistirse al silencio $(8 c)$, romperlo $(8 j)$, oponerse al desafuero $(8 b)$ y repudiar el abuso del poder $(8 k)$. Cuando los participantes en la marcha fueron codificados como objetos, se les trató como pacientes, en un caso fueron reunidos $(8 a, 8 f)$ por AMLO, en tanto que en otro fueron movilizados en su calidad de tropas $(8 h, 8 i)$.

Todos los diarios hablaron de Andrés Manuel López Obrador y los miles de participantes que anónimamente participaron ese día en la marcha. Sin embargo, nadie o casi nadie habló de los otros participantes, aquellos que sin ser nombrados estaban presentes, aquellos cuyas acciones motivaron la marcha; los adversarios de AMLO, aquellos cuyo abuso de poder se repudió, aquellos que desaforaron, aquellos que generaron el encono que se pedía parar; el gobierno federal -en específico Vicente Fox Quesada, entonces presidente de la república- y sus 
Tabla 8. Cómo se refirieron los encabezados a los manifestantes

a) Desde esta madrugada López Obrador regresó a trabajar en su oficina; logra reunir a miles en Marcha del Silencio (La Prensa)

b) Cientos de Miles vs. Desafuero (Excélsior)

c) Marcha que se resistió al silencio (El Universal)

d) Exhorta a sus adversarios a deponer el encono y anuncia plan de Gobierno ante miles de marchistas (El Sol de México)

e) Llama AMLO a poner fin al encono Marcharon al Zócalo cientos de miles (Milenio Diario)

f) López Obrador en marcha multitudinaria / Reúne a cientos de miles de personas y propone tregua para emprender los cambios que requiere el país (Impacto El Diario)

g) Cientos de miles en la marcha (Diario de México)

h) Mueve Tropas

Marchan miles con AMLo (Metro)

i) Moviliza 'tropas' y regresa al GDF

Marchan cientos de miles por AMLO; modera su discurso y anuncia que hoy supervisará obras (Reforma)

j) Rompen el silencio

La marcha convocada por AMLO para protestar por el desafuero se convirtió en un mitin de apoyo políticoelectoral $(E l M)$

k) Más de un millón repudiaron el abuso del poder (La Jornada)

instancias - la PGR en particular-, los senadores y diputados - sobre todo los legisladores del PAN y el PRI- que votaron a favor del desafuero del entonces jefe de Gobierno del Distrito Federal al alegar inconstitucionalidad en sus actos. El Sol de México fue el único periódico que nombró explícitamente y se ocupó en una nota de primera plana - que no formaba parte del titular principal- de los adversarios:

\section{Ignora Fox la marcha}

- Prefiere hablar del nuevo Papa, en su rancho

- Guardan silencio Santiago Creel y el PaN

- Ni nos preocupa ni nos espanta, dicen priistas ( $E l$ Sol de México).

El silencio de los adversarios se complementa con el silencio sobre los adversarios. El discurso de los titulares de prensa construye un escenario en el que los adversarios, con excepción de la PGR, no se nombran explícitamente, aunque están ahí, como se advierte en la tabla 9.
El lector debe inferir contra quién sería la supuesta revancha, el odio o la venganza $(9 a, 9 d)$, a quién se reta $(9 b)$, de dónde viene el encono $(9 b, 9 c, 9 d$, $9 e)$, quién decretó el desafuero $(9 b, 9 j)$, cuál es el delito de que se le acusa $(9 c, 9 h)$, quiénes son sus adversarios $(9 d)$, quién lo descalifica $(9 e)$, a quién va dirigido el discurso conciliador $(9 f, 9 g)$, a quién se le pide o propone el pacto y la tregua $(9 g, 9 i, 9 j)$, quién(es) piensa(n) distinto $(9 g)$, quiénes son los “otros" que dañarían a México $(9 g)$, quiénes abusaron del poder $(9 k)$, quiénes tienen miedo o se alarman $(9 g, 9 k)$, quién propone y cuál es el otro proyecto de nación $(9 j, 9 k)$. En buena medida, los actores que participaron en la "Marcha del Silencio", las acciones que realizaron, así como los discursos que se pronunciaron en ella respondían a otros actores, acciones y discursos que no estaban presentes y que no fueron nombrados explícitamente en los titulares de prensa. Para reconstruirlos el lector necesita saber el contexto y la historia que siguió el proceso de desafuero que dio pie a la histórica concentración del 24 de abril de 2005. 
Tabla 9. Implicaciones sobre los adversarios

a) Propone un pacto sin revanchismos / Todos lo quieren desaforadamente / Saldo blanco en la concentración / No odiamos ni buscamos venganzas (La Prensa)

b) López Retador: Reasumirá hoy Llama a Deponer el Encono / Cientos de Miles vs. Desafuero (Excélsior)

c) Pide López Obrador detener encono Incurrirá en delito: PGR / (El Universal)

d) Plantea AmLo pacto de unidad Pide no temer a su proyecto de izquierda; "no odiamos ni buscamos venganza" / Exhorta a sus adversarios a deponer el encono y anuncia plan de Gobierno ante miles de marchistas (El Sol de México)

e) Llama AмLO a poner fin al encono "Sufragio efectivo, no descalificación" (Milenio Diario)

f) Discurso conciliador de AMLO; ofrece no volver al estatismo (El Financiero)

g) Conciliador, PIDE PACTO

Reúne a cientos de miles de personas y propone tregua para emprender los cambios que requiere el país / "Pensamos distinto, pero no hay motivo para que nadie se alarme; no hay que imaginar cosas que no van a suceder" / "No seremos nosotros los que dañemos a México" (Impacto El Diario)

h) Hoy regresa al GDF; será un delito: PGR (El Gráfico)

i) Propone un pacto con sectores (Diario de México)

j) La marcha convocada por AMLO para protestar por el desafuero se convirtió en un mitin de apoyo políticoelectoral / Con miras al 2006 detalla López Obrador su proyecto alternativo de nación y llama a crear un pacto social para realizar cambios en el país $(E l M)$

$64 \quad$ k) Más de un millón repudiaron el abuso del poder AMLO: miedo irracional al proyecto alternativo de país (La Jornada)

\section{CONCLUSIONES}

El discurso periodístico proporciona un punto de vista sobre el mundo y la naturaleza de la existencia humana y desempeña, como cualquier otro discurso, un papel esencial en la creación de maneras singulares de estar en el mundo. Las voces editoriales -directivos, reporteros, columnistas, analistas, fotógrafos, editores, etcétera- hacen uso de la gama de posibles elecciones de que disponen los hablantes para satisfacer sus objetivos en un proceso comunicativo que tiene, en buena medida, el fin de construir afinidades y diferenciaciones con sus lectores. Las estrategias puestas en juego que tienen lugar en la actividad periodística son producto de complejos procesos de socialización y forman parte del tejido social.

Los titulares de prensa pueden ser considerados un subtipo de discurso periodístico en tanto se distinguen del resto por una serie de características formales y de contenido. Gráficamente, sobresalen del cuerpo del texto por la tipografía con la que se los codifica y adquieren formas lingüísticas singulares que responden a un doble requerimiento: la brevedad en la forma ligada al máximo contenido implícito posible. Estas formas, además, deben resultar de alguna manera llamativas a los potenciales lectores. En los titulares, más que en ningún otro lugar del discurso periodístico, el editor apela al contexto en su más amplia extensión. El lector debe tener acceso al contexto cultural, social y político para poder descifrar lo cifrado en ellos. Son un lugar privilegiado para observar el funcionamiento del lenguaje entendido como una forma compleja de comportamiento o acción social mediante la cual se construyen significados. Su análisis nos permite indagar las distintas estrategias que despliegan los 
hablantes y las dinámicas lingüísticas que se observan en el proceso de generación del significado en tanto éstas constituyen formas de explotar la intersección entre lo implícito y lo explícito.

La marcha del 24 de abril de 2005 constituyó un acontecimiento significativo en la vida política y social del país. Prueba de ello es que al día siguiente ocupaba los titulares de la primera plana en todos los principales diarios de circulación nacional, hecho que pocas veces sucede tan fehacientemente. Se trataba de un evento inusual: la movilización de ciudadanos en una manifestación pública directa y abierta de rechazo a una manera de hacer política por parte de un gobierno federal, el primero de extracción panista en la historia del país. Había tenido actores y acciones específicas que de una u otra manera aparecieron en los titulares conformando un conjunto de temas constantes dentro de la heterogeneidad que se observa en los titulares: la marcha misma - destacable más por la cantidad de participantes o la participación de AMLO en el evento que por lo significativo de esta multitudinaria expresión ciudadana- y Andrés Manuel López Obrador - su regreso, su actitud conciliadora, el lanzamiento de candidatura-.

La incipiente, naciente, titubeante, joven o inexperta democracia mexicana logró hacerse imponer sobre los autoritarismos que querrían limitarla para el adorno de discursos políticamente correctos y, por ende, henchidos de democracia. Por ello, la inclusión de esta nota en primera plana parecía lógica dado el clima de opinión que entonces se experimentaba en el país y en la cual la maniobra política del gobierno federal para impedir la postulación de López Obrador como candidato al año siguiente había quedado suficientemente expuesta. No obstante, valió la pena revisar cuidadosamente hacia dónde se dirigió, en su conjunto, el sentido de esta masiva exigencia por una actuación democrática. Así, y como ha quedado demostrado en varios enfoques analíticos de estos materiales, la marcha fungió mayoritariamente como un elemento de acompañamiento en un ritual de destape electoral que, si bien era peculiar al darse a conocer desde una insólita posición de desafuero político, no rompía con los cánones políticos y mediáticos que han logrado imponerse en este país por cuanto corresponde a sus diversos episodios electorales. Con todo y su condición de desaforado, de gobernante depuesto, de integrante de un partido de izquierda, la prensa dio relevancia al destape de López Obrador y se desdibujó mayoritariamente a los cientos de miles de personas que marchaban para exigir democracia.

La excepción detectada en el tabloide La Prensa, donde se cedió la primera plana a la unción de Benedicto XVI, no parece del todo ajena al manejo político donde el interés suele enfocarse en los sujetos: en la contraportada, y casi en el mismo encuadre que el nuevo Papa, e incluso con un mismo ademán corporal, con la mano derecha en alto, López Obrador y el pontífice se erigían, triunfantes y venerados, por encima de cientos de miles que les rendían pleitesía. En relación con la forma en que operan las reglas políticas, Fairclough (1995: 182) sostiene que, para volverse un actor en el terreno político, cualquier clase o grupo de personas debe encontrar políticos profesionales que lo representen, lo cual significa que, paradójicamente, deben estar políticamente desposeídos para estar políticamente representados. Así, a ocho años de distancia, una nueva lectura de los encabezados de esta marcha memorable confirma la hipótesis que sirvió de punto de partida para nuestra exploración: en una abrumadora mayoría, la prensa no estaba preparada para dar relevancia a una auténtica expresión democrática; optó, en cambio, por destacar el sentido electoral de este episodio.

\section{BIBLIOGRAFÍA}

Armentia Vizuete, José Ignacio y José María Caminos Marcet, 2003, Fundamentos de periodismo impreso, Ariel, Barcelona.

Aziz Nassif, Alberto, 2007, "El retorno del conflicto. Elecciones y polarización política en México", en Desacatos. Revista de Antropología Social, núm. 24, pp. 13-54. 
Comrie, Bernard, 1996, “Markedness”, en Jef Verschueren, Jan-Ola Östman, Jan Blommaert y Chris Bulcaen (eds.), Handbook of Pragmatics, John Benjamins Publishing Company, Ámsterdam, Filadelfia.

Chilton, Paul y Christina Schäffner (eds.), 2002, Politics as Talk and Text: Analytic Approaches to Political Discourse. Discourse Approaches to Politics, Society and Culture, John Benjamins Publishing Company, Filadelfia.

2003, "Discurso y política”, en Teun A. van Dijk (comp.), El discurso como interacción social. Estudios sobre el discurso II. Una introducción multidisciplinaria, Gedisa, Barcelona.

Fairclough, Norman, 1995, Media Discourse, Arnold, Londres, Nueva York.

— y Ruth Wodak, 2000, "Análisis crítico del discurso", en Teun A. van Dijk (comp.), El discurso como interacción social. Estudios sobre el discurso. II. Una introducción multidisciplinaria, Gedisa, Barcelona, pp. 367-404.

Foucault, Michel, 1979, Microfísica del poder, Las Ediciones de la Piqueta, Madrid.

Hopper, P. J. y S. Thompson, 1980, "Transitivity in Grammar and Discourse”, en Language, núm. 56, pp. 251-299.

Kress, Gunther y Theo van Leeuwen, 1998, "Front Pages: (the Critical) Analysis of Newspaper Layout”, en Allan Bell y Peter Garrett, Approaches to Media Discourse, Blackwell Publishers, Oxford, pp. 186-219.

Kurzon, Dennis, 1998, Discourse of Silence, John Benjamins Publishing Company, Ámsterdam, Filadelfia.

Lyons, John, 1981, Lenguaje, significado y contexto, Paidós Comunicación, Barcelona.

Martínez Albertos, José Luis, 1974, Redacción periodística. Los estilos y los géneros en la prensa escrita, ATE, Barcelona.
Reyes, Graciela, 1984, Polifonía textual. La citación en el relato literario, Gredos, Madrid.

Rivadeneira Prada, Raúl, 1980, Periodismo. La teoría general de los sistemas y la ciencia de la comunicación, Trillas, México.

Rodríguez Saldaña, Elsa, 2008, "La marcha de protesta como un texto multimodal", tesis de doctorado, Centro de Investigaciones y Estudios Superiores en Antropología Social, México.

Salgado Andrade, Eva, 2003, El discurso del poder. Informes presidenciales en México (1917-1946), Centro de Investigaciones y Estudios Superiores en Antropología Social, Porrúa, México.

— , 2009, Qué dicen los periódicos, Centro de Investigaciones y Estudios Superiores en Antropología Social, México.

Saville-Troike, Muriel, 1985, “The Place of Silence in an Integrated Theory of Communication”, en Deborah Tannen y Muriel Saville-Troike (eds.), Perspectives on Silence, Ablex, Norwood, pp. 3-18.

van Dijk, Teun, 1980, Estructuras y funciones del discurso, Siglo XXI, México.

— 1990, La noticia como discurso. Comprensión, estructura y producción de la información, Paidós, Barcelona.

van Leeuwen, Theo, 1993, "Genre and Field in Critical Discourse Analysis", en Discourse and Society, núm. 4, pp. 193-223.

Wårvik, Brita, 1996, “Grounding”, en Jef Verschueren, Jan-Ola Östman, Jan Blommaert y Chris Bulcaen (eds.), Handbook of Pragmatics, John Benjamins Publishing Company, Ámsterdam, Filadelfia. 